Universitäts-Kinderklinik Zürich

Medizinische Klinik

Direktor: Prof. Dr. med. F. H. Sennhauser

Abteilung Pneumologie

Leiter: Dr. med. A. Möller

Arbeit unter Leitung von Prof. Dr. med. Johannes H. Wildhaber

\title{
Facemasks and Aerosol Delivery In Vivo
}

\section{INAUGURAL-DISSERTATION}

zur Erlangung der Doktorwürde der Medizinischen Fakultät

der Universität Zürich

\author{
vorgelegt von \\ Simone Erzinger \\ von Buchberg SH
}

Genehmigt auf Antrag von Prof. Dr. med. F.H. Sennhauser 


\section{Publikation}

Name: Journal of Aerosol Medicine

Jahrgang: $\quad 2007$

Band: $\quad$ Volume 20, Number s1

Seitenzahl: $\quad$ S78-S84 


\section{Curriculum vitae}

\section{Simone Erzinger von Buchberg, SH}

11.10.1984

1991-1994

1994-1997

1997-2003

2003-2009

$09 / 2009$
Geboren in Bülach, Heimatort Buchberg SH

Primarschule in Embrach (1.-3. Klasse)

Primarschule in Winkel (3.-6. Klasse)

Kantonsschule Zürcher Unterland, Bülach

(Altsprachliches Profil mit Schwerpunktfach Englisch

und Ergänzungsfach Biologie)

Medizinstudium an der Universität Zürich

Staatsexamen an der Universität Zürich 


\title{
Facemasks and Aerosol Delivery In Vivo
}

\author{
SIMONE ERZINGER, ${ }^{1}$ KAREN G. SCHUEEPP, M.D., $, 1,3$ \\ JOANNE BROOKS-WILDHABER, MPH, ${ }^{2}$ SUNALENE G. DEVADASON, Ph.D., ${ }^{3}$ \\ and JOHANNES H. WILDHABER, M.D., Ph.D. ${ }^{1}$
}

\begin{abstract}
It has been shown in vitro that even a small air leak in the facemask can drastically reduce the efficiency of drug delivery. In addition, it has been shown that drug deposition on the face does significantly add to overall drug loss and has the potential of local side effects. The aim of this study is therefore to verify these findings in vivo. Eight asymptomatic recurrently wheezy children, aged 18-36 months, inhaled a radiolabeled salbutamol formulation either from a pressurized metered-dose inhaler through a spacer with attached facemask or from a nebulizer with attached facemask. Drug deposition of radiolabeled salbutamol was assessed with a gamma camera and expressed as a percentage of the total dose. Lung deposition expressed as a percentage of the total dose (metered dose and nebulizer fill, respectively) was $0.2 \%$ and $0.3 \%$ in children who inhaled with a non-tightly fitted facemask. Lung deposition was $0.6 \%$ and $1.4 \%$ in screaming children with a tightly fitted facemask and between $4.8 \%$ and $8.2 \%$ in patients breathing normally. Overall mask deposition was between $0.8 \%$ and $5.2 \%$. Overall face deposition was between $2.6 \%$ and $8.4 \%$. The results from this pilot study support the results found in in vitro studies, where a facemask leak greatly reduces drug delivery to the patient.
\end{abstract}

Key words: aerosol delivery, face mask, inhalation therapy, lung deposition, radiolabeled aerosols, scintigraphy studies

\section{INTRODUCTION}

Y OUNG CHILDREN, generally under the age of 3 years, are not able to use a mouthpiece for inhalation therapy and therefore, they inhale through a facemask using various delivery devices, such as pressurized metered-dose inhalers (pMDIs) with spacer or nebulizers. There are several in vitro studies which have looked at the ef- fect of a facemask leak on aerosol delivery. ${ }^{(1-5)} \mathrm{A}$ $50 \%$ and $80 \%$ reduction in drug delivery were found when the mask of a nebulizer was removed 1 and $2 \mathrm{~cm}$, respectively, from the face. ${ }^{(2)}$ This finding is true for both pMDI with spacer and nebulizer. ${ }^{(4)}$ It has also been shown, that even a small air leak in the facemask of a pMDIspacer-facemask combination can drastically reduce the efficiency of drug delivery. ${ }^{(5)}$ In addi-

\footnotetext{
${ }^{1}$ Division of Respiratory Medicine, University Children's Hospital Zürich and ${ }^{2}$ Alpine Children's Hospital, Davos, Switzerland.

${ }^{3}$ Perth Medical Aerosol Research Group, Department of Paediatrics, University of Western Australia, Perth, Australia.
} 
tion it has been shown that the efficiency of drug delivery can be improved using a round facemask with a flexible rim. ${ }^{(6)}$

The question arises whether in vivo results mirror in vitro results. There are no in vivo deposition studies that have looked specifically at the effect of facemask leaks. On the contrary, in the few performed radiolabeled aerosol deposition studies in this age group, measures were undertaken to avoid facemask leaks, mainly by fitting the facemask tightly on the child's face and by putting vaseline around the facemask rim to ensure a complete seal. ${ }^{(7-9)}$ In a study using the Aerochamber spacer with corresponding facemask in 15 infants and young children from 3 months to 5 years of age the mean deposition of radiolabeled salbutamol was $1.97 \%$ in the lungs, $1.28 \%$ in the oropharynx and $1.11 \%$ in the stomach. ${ }^{(7)}$ Using a non-electrostatic spacer (detergent washed Babyhaler spacer with corresponding facemask) lung deposition has been shown to be much higher $(16.4 \%) .{ }^{(8)}$ In a comparison of radiolabeled salbutamol delivery lung deposition has been shown to be similar through the Aerochamber spacer with corresponding facemask and through a nebulizer with a Pari baby facemask. ${ }^{(9)}$ In this study, it has been shown that the amount of drug deposited in the mask is relatively small and varies between the two masks used, with a mean (SD) facemask deposition of $2.4 \%$ (1.8) for the Pari baby facemask and $4.5 \%$ (2.1) for the Aerochamber mask. A dramatic reduction of drug delivery has been reported when the facemask was not tightly fitted to the face. ${ }^{(10)}$ Drug deposition on the face has generally been included in overall oropharyngeal deposition and has never been calculated separately. However, by visualizing scintigraphic pictures, it is clearly depicted that a significant portion of the drug is deposited on the face outlined by the shape of the mask used. The aim of this pilot study was to analyze face drug deposition from young children using a pMDI/spacer combination or a nebulizer, both with facemask, for the inhalation of radiolabeled salbutamol.

\section{METHODS}

\section{Subjects}

In vivo lung deposition was studied in eight asymptomatic, recurrently wheezy children (five boys) aged 18-36 months (a: 26 months, b: 28 months, c: 20 months, d: 24 months, e: 31 months, f: 18 months, g: 26 months, and h: 36 months of age, respectively). Written informed consent was obtained from all parents, and the study was approved by the local hospital ethics committee.

\section{Study design}

The children inhaled technetium ${ }^{99}\left(\mathrm{Tc}^{99}\right)$-radiolabelled salbutamol (Ventolin, Allen Hanburys, Sydney, Australia). Four children inhaled $2 \mathrm{~mL}$ of radiolabeled salbutamol solution (Ventolin, $1 \mathrm{mg} / \mathrm{mL}$, Allen Hanburys, Sydney, Australia) from an open vent-assisted nebulizer (Pari Baby with Pari facemask no. 2) driven by a compressor (Pari Proneb Turbo, Pari Boy type 38). Four children inhaled four puffs from a radio-

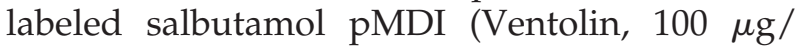
actuation; Allen Hanburys, Sydney, Australia) through a plastic holding chamber (Aerochamber with an Aerochamber $2^{\text {cd }}$ generation face mask; Trudell Medical, Hamilton, Canada). To ensure a tightly fitting face mask, the rim of the mask was covered with vaseline. In two infants, a seal could not be achieved due to the lack of cooperation.

The dose in the nebulizer was quantified before, and the dose in the pMDI canister was quantified before and after the inhalation procedure with an ionization chamber (Atomlab 200 dose calibrator; Gammasonics, Sydney, NSW, Australia). The dose of $\mathrm{Tc}^{99}$ to be given to each patient was assessed before the inhalation procedure was performed, so that patients would not receive a dose exceeding $2 \mathrm{MBq}$ in total dose. All patients inhaled tidally through the nebulizer for $5 \mathrm{~min}$ and were allowed five tidal breaths between each actuation of the pMDI. The pMDI was shaken between actuations. A filter (Curity Anaesthesia Filter, Kendall, MA) was inserted at the expiratory valves of both the nebulizer and the holding chamber to collect the expired aerosol.

Quantification of the distribution of activity depositing in the patients was done in the following way. A flood source containing approximately $37 \mathrm{MBq} \mathrm{Tc}{ }^{99}$ was used to obtain values for attenuation of activity caused by absorption by body tissues. Because attenuation of activity is dependent on size and body mass, and these parameters varied greatly between patients, an attenuation value was determined for each patient and each region of interest. After the inhalation pro- 
cedure was performed, anterior and posterior images of the chest and the abdomen were obtained with lateral images of the upper airway with a gamma camera (Dual Head GCA-7200A; Toshiba Corp., Tochigi-Ken, Japan). Collection times were $2 \mathrm{~min}$ for each of the images. Areas of interest were defined for each of the images, and separate count rates were determined for the right and left lungs, stomach, esophagus, throat, mouth, and face. Each count rate was corrected for background counts and attenuation, and the geometric means of corresponding anterior and posterior count rates were calculated. For the nebulizer, the dose deposited in the lungs was then expressed as a percentage of the total nebulizer fill dose. For the pMDI and spacer, the dose deposited in the lungs was expressed as a percentage of the total metered dose. Gastrointestinal deposition was defined as the total dose deposited in the mouth, throat, esophagus and stomach. The ratio face/lung deposition was defined as therapeutic index.

\section{Labeling of salbutamol}

Nebulizer solution. A total of $15 \mathrm{MBq}$ of $\mathrm{Tc}^{99}$ bound to diethylenetriamine penta-acetic acid was added to $2 \mathrm{~mL}$ of salbutamol solution. The droplet spectrum from the nebulizer was measured with a laser particle sizer (Master Sizer X Version 1.2a; Malvern Instruments $\mathrm{GmbH}$, Herrsching, Germany).

Salbutamol pMDI. For the labeling of a canister, 500-600 MBq Tc ${ }^{99}(0.5-1.0 \mathrm{~mL})$ was eluted from a generator (Technetium 99m Generator; Australian Radioisotopes, Lucas Heights, NSW, Australia) and made up to $2 \mathrm{~mL}$ with $20 \% \mathrm{NaCl}$. The $2 \mathrm{~mL}$ was then poured into a separating funnel and shaken together with $4 \mathrm{~mL}$ of ethyl methyl ketone (butanone). The two phases were allowed to separate, and the top layer ( $\mathrm{Tc}^{99}$ in butanone) was collected in a new pMDI canister. The collected butanone containing the radioactivity was evaporated for $12 \mathrm{~min}$ in a nitrogen flow (9-13 $\left.\mathrm{L} \cdot \min ^{-1}\right)$. The canister was placed into an oven for half an hour at a temperature of $73-85^{\circ} \mathrm{C}$ to evaporate the water content. The canister was then placed in dry ice to be cooled. A frozen (dry ice) commercial pMDI was opened with a pipe cutter (TC1000, Imperial Eastman), and the content was poured into the cooled canister containing the radioactivity and immediately crimped
(Crimper Type 555G, Pamasol; Willi Mäder AG, Pfäffikon, Switzerland). The closed canister was subsequently shaken for half an hour. In vitro assessment of radiolabeling was done by measuring in vitro particle size distribution and total drug delivery with a multistage liquid impinger (MSLI; Copley, Nottingham, UK) before and after the children were tested. The sizes of particles deposited on stages $1,2,3$, and 4 were $>13 \mu \mathrm{m}$, 6.8-13 $\mu \mathrm{m}, 3.1-6.8 \mu \mathrm{m}$, and $<3.1 \mu \mathrm{m}$, respectively. Ten actuations of radiolabeled salbutamol from the pMDI were drawn through the MSLI at a continuous flow of $60 \mathrm{~L} \cdot \mathrm{min}^{-1}$. The actuator, the glass throat, and the four stages of the MSLI were washed with $45 \mathrm{~mL}$ of methanol. A total of $5 \mathrm{~mL}$ of $0.1 \mathrm{~mol} / \mathrm{L} \mathrm{NaOH}$ was added to each wash. The absorbance of salbutamol (wavelength $246 \mathrm{~nm}$ ) was measured in each wash with a spectrophotometric method. The concentration of salbutamol was calculated with the absorbance of a solution containing a known concentration of salbutamol. The standard curve for salbutamol was linear $\left(r^{2}=1.00\right)$ for concentrations between 0 and $21 \mu \mathrm{g}$. The distribution of radioactivity in the different washes was measured in an ionization chamber (Atomlab 200 dose calibrator; Gammasonics, Sydney, NSW, Australia). The output and the particle size distribution of $\mathrm{Tc}^{99}$-labeled salbutamol from the study pMDIs $(n=4)$ were then compared with the particle size distribution of salbutamol from commercial Ventolin pMDIs $(n=4)$. This comparison was done to confirm that $99 \mathrm{mTc}$ acts as a suitable marker for salbutamol.

\section{RESULTS}

There was a good correlation between label and drug delivery from the pMDI with the following mean (SD) output of particles of $<6.8 \mu \mathrm{m}$ expressed as a percentage of the total metered dose: 47.8 (3.2), 48.9 (4.1), and 47.6 (2.8) for unlabeled drug, labeled drug, and radiolabeled drug, respectively. Radiolabeled drug deposition for each patient is shown in Table 1 and Figure 1. Lung deposition expressed as a percentage of the total dose was $0.2 \%$ and $0.3 \%$ in children who inhaled with a non-tightly fitted facemask (leak; patients $a$ and $b$ ). The deposition was $0.6 \%$ and $1.4 \%$ in screaming children with a tightly fitted facemask (screaming; patients $\mathrm{c}$ and $\mathrm{d}$ ) and between $4.8 \%$ and $8.2 \%$ in patients quietly inhaling (qui- 
Table 1. Drug Deposition in Young Children

\begin{tabular}{|c|c|c|c|c|c|c|}
\hline \multirow[b]{2}{*}{ Age/sex/device } & \multirow[b]{2}{*}{ Lung } & \multirow[b]{2}{*}{ Gastrointestinal } & \multicolumn{3}{|c|}{ Deposition } & \multirow[b]{2}{*}{ Ratio (face/lung) } \\
\hline & & & Mask & Face & Ratio (face/patient) & \\
\hline \multicolumn{7}{|l|}{ Facemask leak: } \\
\hline (a) $26 ; \mathrm{m}$; pMDI & 0.2 & 5.8 & 1.2 & 2.6 & 0.4 & 13 \\
\hline (b) $28 ; \mathrm{m}$; nebulizer & 0.3 & 4.7 & 2.4 & 3.1 & 0.6 & 10 \\
\hline \multicolumn{7}{|c|}{ No facemask leak, screaming: } \\
\hline (c) 20; f; pMDI & 0.6 & 15.8 & 5.2 & 7.9 & 0.5 & 13 \\
\hline (d) $24 ; \mathrm{m}$; nebulizer & 1.4 & 19.7 & 0.9 & 8.4 & 0.4 & 6 \\
\hline \multicolumn{7}{|c|}{ No facemask leak, quietly inhaling: } \\
\hline (e) $31 \mathrm{~m}$; pMDI & 7.4 & 12.2 & 4.4 & 5.2 & 0.3 & 0.7 \\
\hline (f) $18 ; \mathrm{f}$; pMDI & 5.2 & 13.8 & 3.2 & 7.8 & 0.4 & 1.5 \\
\hline (g) 26 ; f; nebulizer & 4.8 & 9.3 & 1.8 & 4.8 & 0.3 & 1 \\
\hline (h) $36 ; \mathrm{m}$; nebulizer & 8.2 & 10.1 & 0.8 & 3.6 & 0.1 & 0.4 \\
\hline
\end{tabular}

Drug deposition expressed as a percentage of the total dose in a young child: (a) inhaling with a pMDI/spacer through a non-tightly fitted face mask, (b) inhaling with a nebulizer through a non-tightly fitting face mask, (c) inhaling with a pMDI/spacer through a tightly fitted face mask, screaming during inhalation, (d) inhaling with a nebulizer through a tightly fitted face mask, screaming during inhalation, (e and f) inhaling with a pMDI/spacer through a tightly fitted face mask, quietly inhaling, and ( $\mathrm{g}$ and $\mathrm{h}$ ) inhaling from a nebulizer through a tightly fitted face mask quietly inhaling.

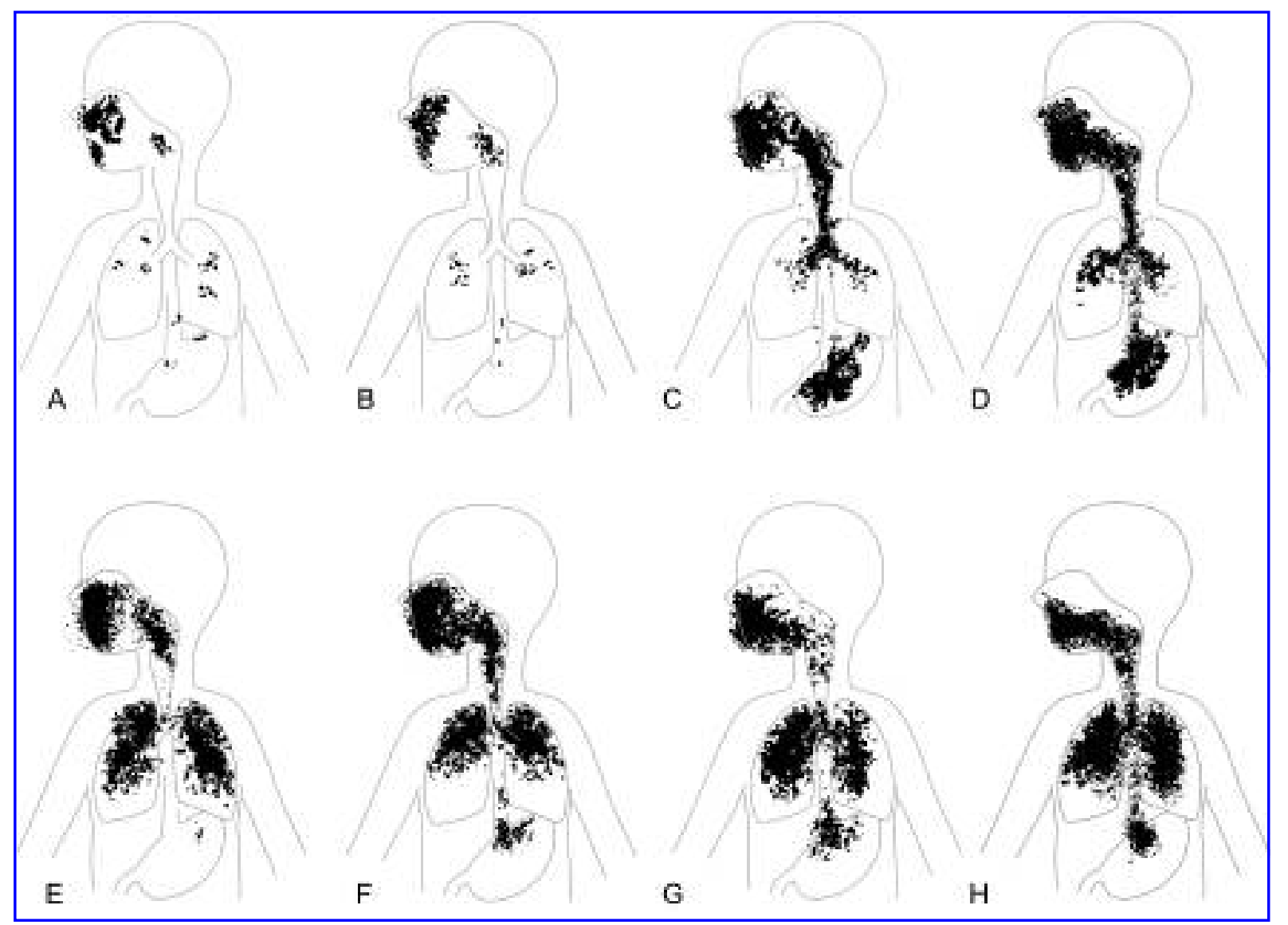

FIG. 1. Drug deposition of radiolabeled Salbutamol in a young child (A) inhaling with a pMDI/spacer through a non-tightly fitted facemask, (B) inhaling with a nebulizer through a non-tightly fitted facemask, (C) inhaling with a pMDI/spacer through a tightly fitted facemask, screaming during inhalation, (D) inhaling with a nebulizer through a tightly fitted facemask, screaming during inhalation, $(\mathrm{E}, \mathrm{F})$ inhaling with a pMDI/spacer through a tightly fitted facemask, quietly inhaling, and $(\mathrm{G}, \mathrm{H})$ inhaling from a nebulizer through a tightly fitted facemask, quietly inhaling. 
etly inhaling; patients e, f, g, and h). Mask deposition was between $0.8 \%$ and $5.2 \%$. Face deposition was between $2.6 \%$ and $8.4 \%$. The ratio face/patient deposition and especially the ratio face/lung deposition as a measure of therapeutic index were much higher in quietly inhaling children.

\section{DISCUSSION}

Our in vivo pilot study in children inhaling with a facemask supports the results found in in vitro studies, where a facemask leak greatly reduces drug delivery to the patient. ${ }^{(1-6)}$ In addition, face drug deposition is significant. In comparison to a mask leak and face deposition, the deposition in the mask is of a lesser impact on overall drug loss.

The aim of an inhaled therapy is to effectively deliver drug to its site of action. The administration of aerosolized drug to children in general and to young children in particular has been shown to be difficult with only a very small amount of drug reaching the airways. ${ }^{(11)}$ This may be partly explained by the age specific breathing patterns as well as airway anatomy. It has been shown that lung deposition could be greatly improved when these parameters are taken into account. ${ }^{(10,12,13)}$ However, lung deposition in young children has been shown to be low, mainly due to drug loss in the device itself (nebulizer and spacer). ${ }^{(11)}$ Drug loss in general reduces the drug available at the site of action. Surprisingly, there is not much in vivo data on the influence of a facemask on overall drug deposition. A facemask is not easily accepted by young children and screaming during inhalation reduces parental compliance. ${ }^{(14)}$

It has been shown in vitro that the inhaled mass from a nebulizer with facemask is low with a high facial drug deposition and a variable eye drug deposition, where the eyes seem to be a focal point of deposition. ${ }^{(15)}$ Our in vivo data suggest a higher face deposition than found in vitro. Sagwan et al. found a facial deposition at $0.44-2.34 \%$ of nebulizer charge, with eye deposition at $0.09-1.78 \% .^{(15)}$ This difference may be explained by the different surface proprieties, where the skin may attract more aerosols than the surface of the in vitro model. Another explanation may be that in in vivo studies using two dimensional scintigraphy there could be some overlap with mouth deposition and hence, an overestimation of facial drug deposition. A tight seal was achieved in the present in vivo studies by putting vaseline around the mask rim. Therefore we could not reproduce the finding of focal eye deposition from in vitro results. Looking at the scintigraphy pictures of patient $a$ and $b$, inhaling with a non-tightly fitted facemask, there seems to be a focal eye deposition. We could therefore illustrate in these two non-cooperative young children, that a facemask leak greatly reduces deposition within the patient.

Drug loss in general reduces the drug available at the site of action. Therefore, it is crucial to improve the interface between the device and the patient in general and the facemask in particular. ${ }^{(17)}$ In addition, face drug deposition bears the potential of local side effects. Some data from the literature suggests that local side effects are minimal. $^{(16,17)}$ On the other hand, there is a study that has shown local side-effects of inhaled corticosteroids to be common in asthmatic children of all ages, and that the device used constitutes the most influential factor. ${ }^{(18)}$

In summary, a facemask should have an effective seal, be flexible and soft with a large inward curved rim and have a minimal dead space. Despite these technical considerations, patient cooperation remains the main limiting factor in aerosol therapy in young children. It would be useful to have more data on in vivo aerosol deposition from various devices using various facemasks, to assess the influence of mask design on drug deposition in general and on face deposition in particular. These insights would inturn lead to optimal inhalation therapy in young children.

\section{REFERENCES}

1. Hayden, J.T., N. Smith, D.A. Woolf, P.W. Barry, and C. O'Callaghan. 2004. A randomised crossover trial of facemask efficacy. Arch. Dis. Child. 89:72-73.

2. Everard, M.L., A.R. Clark, and A.D. Milner. 1992. Drug delivery from jet nebulisers. Arch. Dis. Child. 67:586-591.

3. Amirav, I., and M.T. Newhouse. 2001. Aerosol therapy with valved holding chambers in young children: importance of the facemask seal. Pediatrics 108:389394.

4. Smaldone, G.C., E. Berg, and K. Nikander. 2005. Variation in pediatric aerosol delivery: importance of facemask. I. Aerosol Med. 18:354-363.

5. Esposito-Festen, J.E., B. Ates, F.J.M. van Vliet, A.F.M. Verbraak, J.C. de Jongste, and H.A.W.M. Tiddens. 
2004. Effect of a facemask leak on aerosol delivery from a pMDI-spacer system. L. Aerosol Med. 17:1-6.

6. Esposito-Festen, J.E., B. Ates, F.J.M. van Vliet, W.C.J. Hop, and H.A.W.M. Tiddens. 2005. Aerosol delivery to young children by pMDI-spacer: is facemask design important? Pediatr. Allergy Immunol. 16:348-353.

7. Tal, A., H. Golan, N. Grauer, M. Aviram, D. Albin, and M.R. Quastel. 1996. Deposition pattern of radiolabeled salbutamol inhaled from a metered-dose inhaler by means of a spacer with mask in young children with airway obstruction. L. Pediatr. 128:479-484.

8. Wildhaber, J.H., H.M. Janssens, F. Pierart, N.D. Dore, S.G. Devadason, and P.N. LeSouef. 2000. High-percentage lung delivery in children from detergenttreated spacers. Pediatr. Pulmonol. 29:389-393.

9. Wildhaber, J.H., N.D. Dore, J.M. Wilson, S.G. Devadason, and P.N. LeSouef. 1999. Inhalation therapy in asthma: nebulizer or pressurized metered-dose inhaler with holding chamber? In vivo comparison of lung deposition in children. I. Pediatr. 135:28-33.

10. Schueepp, K.G., S. Devadason, C. Roller, and J.H. Wildhaber. 2004. A complementary combination of delivery device and drug formulation for inhalation therapy in preschool children. Swiss Med. Wkly. 134: 198-200.

11. Schueepp, K.G., D. Straub, A. Möller, and J.H. Wildhaber. 2004. Deposition of aerosols in infants and children. I. Aerosol Med. 17:153-156.

12. Schuepp, K.G., J. Jauernig, H.M. Janssens, H.A. Tiddens, D.A. Straub, R. Stangl, M. Keller, and J.H. Wildhaber. 2005. In vitro determination of the optimal particle size for nebulized aerosol delivery to infants. $L$ Aerosol Med. 18:225-235.

13. Janssens, H.M., A. Krijgsman, T.F. Verbraak, W.C. Hop, J.C. de Jongste, and H.A. Tiddens. 2004. Determining factors of aerosol deposition for four pMDI- spacer combinations in an infant upper airway model. L. Aerosol Med. 17:51-61.

14. Marguet, C., L. Couderc, P. Le Roux, E. Jeannot, V. Lefay, and E. Mallet. 2001. Inhalation treatment: errors in application and difficulties in acceptance of the devices are frequent in wheezy infants and young children. Pediatr. Allergy Immunol. 12:224-230.

15. Sangwan, S., B.K. Gurses, and G.C. Smaldone. 2004. Facemasks and facial deposition of aerosols. Pediatr. Pulmonol. 37:447-452.

16. Bisgaard, H., D. Allen, J. Milanowski, I. Kalev, L. Willits, and P. Davies. 2004. Twelve-month safety and efficacy of inhaled fluticasone propionate in children aged 1 to 3 years with recurrent wheezing. Pediatrics 113:87-94.

17. Berger, W.E., P.Y. Qaqundah, K. Blake, J. RodriguezSantana, A.M. Irani, J. Xu, and M. Goldman. 2005. Safety of budesonide inhalation suspension in infants aged six to twelve months with mild to moderate persistent asthma or recurrent wheeze. I. Pediatr. 146:91-95.

18. Dubus, J.C., C. Marguet, A. Deschildre, L. Mely, P. Le Roux, J. Brouard, L. Huiart, and Reseau de Recherche Clinique en Pneumonologie Pediatrique. 2001. Local side-effects of inhaled corticosteroids in asthmatic children: influence of drug, dose, age, and device. $\underline{\mathrm{Al}}$ lergy 56:944-948.

Address reprint requests to: Johannes Wildhaber, M.D., Ph.D. Head Division of Respiratory Medicine University Children's Hospital Steinwiesstrasse 75 CH-8032 Zürich, Switzerland

E-mail: johannes.wildhaber@kispi.unizh.ch

\section{DISCUSSION}

Beth Laube, Ph.D.: I'd like to ask a technical question: In your images, how do you differentiate between the mask and the face in a lateral view?

Johannes Wildhaber, M.D., Ph.D.: We don't image the mask while it's on the face. It's looked at separately. And because the view is only two-dimensional, and there is an overlap, I really can't properly account for the patterns of deposition; there may be some oral or nasal deposition. That is a problem, but I don't think it influences the results.

Dr. Laube: Then particle deposition on the mask is counted separately?
Dr. Wildhaber: Yes.

Gerald Smaldone, M.D., Ph.D.: I'm seeing these data for the first time, but I'd suggest that we have to think about mechanism, particularly with the Pari baby E-Flow mask, to take but one example. If you use a Vaseline seal and a low-pressure system, I'd think that there is probably some type of flow regime in the mask during expiration whereby the aerosol particles are depositing on the face.

I also wanted to say that in the experiments with the metered dose inhaler (MDI), I was struck by the amount of aerosol that seemed to be deposited in the facial region, which I wouldn't have ex- 
pected solely on the basis of what we know right now about MDIs. I haven't looked at particle deposition in the eyes of infants with the use of radiolabeled particles, but I would think that in a system that is not highly pressurized, the child's breathing is pressurizing the mask, and they may be exhaling particles so as to create the milieu for facial deposition and deposition on the mask during breathing. I think your data are very challenging, but very important, and create a whole new conceptual area because much of the data were not produced with pressurized nebulizers.

Dr. Wildhaber: I will look back and analyze all the data I have. On the basis of simple visualization, though, the data don't look that different. I also thought about the E-Flow mask and the rather low particle output with it in the test, but I'm not sure whether that has an impact. The low flow may influence facial deposition, but I'm not sure that that was the responsible mechanism. Besides this, I was surprised because I expected hardly any facial deposition with the pressurized MDI (pMDI) spacers, and was struck by the amount of aerosol that was deposited on the face with them. I have no explanation for those findings.

Chris O'Callaghan, FRCP, FRCPCH, D.M., Ph.D.: We would very much like to undertake one or two aerosol deposition studies in children. We think that it's very important to determine where an aerosol drug is deposited, because of the therapeutically specific nature of these drugs. Our problem has been in getting ethical approval for studies of this. The factor acting against us is the need for informed consent by parents, who argue that an inhaled radioactive drug may go into their child's lungs and be preferentially deposited at airway bifurcations, which will create radioactive "hot spots" on the affected groups of cells. How can you tell the specific dose of radioactivity being delivered to individual cells? As a result, we have to say that we don't know the dose your child is getting at specific cell sites, but please sign here to indicate that you approve our study. And that is making it difficult for us to do some of the studies we'd like to do.
Dr. Wildhaber: That was exactly the same argument that our ethical committee had, and as a result I can't do such studies in Zurich, either.

Mitchell A. Baran: Dr. Wildhaber, did you by any chance compare your results with the 3-month to 5 -year-old group (mean age, 21 months) with the results that Asher Tal and colleagues evaluated a number of years ago, some of whom had cystic fibrosis?

Dr. Wildhaber: That's the group I showed. It seemed that, visually, their results looked quite similar to ours, but I can't analyze them because you need the full data to do that.

Mr. Baran: Yes, the data for your birth to 24month-old group looked quite similar to the data of Asher, Tal, and colleagues with the AeroChamber ${ }^{\circledR}$ valved holding chamber, despite the fact that they were physically impaired with cystic fibrosis lung disease.

Hettie Janssens, M.D., Ph.D.: It's nice to have a new look at your old data, although I think it is surprising that there is such a substantial deposition on the face. But if I am a bit provocative, I can ask you, "Who cares?" Does it matter if you lose a lot of medication on the face?

Dr. Wildhaber: What you want is to get the drug into the lungs. You don't want to have it on the face. So the issue has to do with efficiency. Obviously, we have to think about side effects when we increase the extraneous deposition, but primarily we want to get the drug into the lungs, and that's really why the facial deposition matters. And I was surprised how significant the facial deposition was.

Dr. Janssens: But you can also do something about it.

Dr. Wildhaber: That was my approach as well. Clearly, you can just wash off that deposition, but now, in looking at the data, I realize it's a significant component of overall deposition. 